\title{
Risk Factors for Acute Kidney Injury Following Cardiac Surgery and Performance of Leicester Score in a Spanish Cohort
}

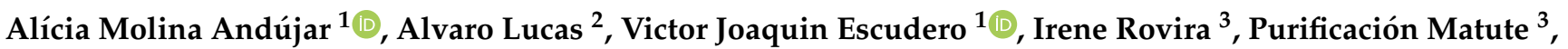 \\ Cristina Ibañez ${ }^{3}$, Miquel Blasco ${ }^{1}$, Elena Sandoval ${ }^{4}$, Jesús Ruiz ${ }^{4}$, Marina Chorda Sánchez ${ }^{5}$, Gaston J. Piñeiro ${ }^{1}$, \\ Eduard Quintana ${ }^{4}$ and Esteban Poch ${ }^{1, *}$
}

check for updates

Citation: Molina Andújar, A.; Lucas, A.; Escudero, V.J.; Rovira, I.; Matute, P.; Ibañez, C.; Blasco, M.; Sandoval,

E.; Ruiz, J.; Chorda Sánchez, M.; et al. Risk Factors for Acute Kidney Injury Following Cardiac Surgery and Performance of Leicester Score in a Spanish Cohort. J. Clin. Med. 2022, 11, 904. https://doi.org/10.3390/ jcm11040904

Academic Editors: Eduardo Tamayo, Christian Ortega-Loubon and Pablo Jorge-Monjas

Received: 21 December 2021

Accepted: 3 February 2022

Published: 9 February 2022

Publisher's Note: MDPI stays neutral with regard to jurisdictional claims in published maps and institutional affiliations.

Copyright: (C) 2022 by the authors. Licensee MDPI, Basel, Switzerland. This article is an open access article distributed under the terms and conditions of the Creative Commons Attribution (CC BY) license (https:// creativecommons.org/licenses/by/ $4.0 /)$.
1 Nephrology and Kidney Transplantation Department, Hospital Clínic, IDIBAPS, University of Barcelona, 08036 Barcelona, Spain; amolinaa@clinic.cat (A.M.A.); vjescudero@clinic.cat (V.J.E.); MIBLASCO@clinic.cat (M.B.); gjpineir@clinic.cat (G.J.P.)

2 Faculty of Medicine and Health Science, Medicine Campus, University of Barcelona, 08036 Barcelona, Spain; alvarolucasi@hotmail.com

3 Anesthesiology Department, Hospital Clínic, University of Barcelona, 08036 Barcelona, Spain; irovira@clinic.cat (I.R.); pmatute@clinic.cat (P.M.); CRIBANEZ@clinic.cat (C.I.)

4 Cardiovascular Surgery Department, Hospital Clínic, University of Barcelona, 08036 Barcelona, Spain; esandova@clinic.cat (E.S.); jeruiz@clinic.cat (J.R.); equintan@clinic.cat (E.Q.)

5 Perfusion Department, Hospital Clinic, University of Barcelona, 08036 Barcelona, Spain; mchorda@clinic.cat

* Correspondence: epoch@clinic.cat; Tel.: +34-932-27-54-00 (ext. 2363)

\begin{abstract}
The incidence of acute kidney injury following cardiac surgery (CSA-AKI) is up to 30\%, and it places patients at an increased risk of death. The Leicester score (LS) is a new score that predicts CSA-AKI of any stage with better discrimination compared to previous scores. The aim of this study was to identify risk factors for CSA-AKI and to assess the performance of LS. A unicentric retrospective study of patients that required cardiac surgery with cardio-pulmonary bypass (CPB) in 2015 was performed. The inclusion criteria were patients over 18 years old who were operated on for cardiac surgery (valve substitution (VS), Coronary Artery Bypass Graft (CABG), or a combination of both procedures and requiring $\mathrm{CPB}$ ). CSA-AKI was defined with the Kidney Disease Improving Global Outcomes (KDIGO) criteria. In the multivariate analysis, hypertension (odds ratio 1.883), estimated glomerular filtration rate (EGFR) $<60 \mathrm{~mL} / \mathrm{min}$ (2.365), and peripheral vascular disease (4.66) were associated with the outcome. Both discrimination and calibration were better when the LS was used compared to the Cleveland Clinic Score and Euroscore II, with an area under the curve (AUC) of 0.721. In conclusion, preoperative hypertension in patients with CKD with or without peripheral vasculopathy can identify patients who are at risk of CSA-AKI. The LS was proven to be a valid score that could be used to identify patients who are at risk and who could benefit from intervention studies.
\end{abstract}

Keywords: acute kidney injury; cardiac surgery; Leicester score; prediction; risk factors; intensive care unit

\section{Introduction}

The incidence of acute kidney injury (AKI) following cardiac surgery is up to 30\%, and between $2 \%$ and $5 \%$ of cases require renal replacement therapy (RRT) during the AKI episode. AKI places patients at a five-fold increased risk of death during admission, and when there is a need for RRT, it is associated with a $50 \%$ mortality [1].

Identifying pre-operative and intraoperative risk factors for cardiac surgery-associated AKI (CSA-AKI) is a vitally important issue for both clinical practice and research in order to detect patients who are at risk and who can be the focus for intervention. Potentially modifiable intraoperative risk factors remain of equal importance since their identification can lead to actions towards them. One of the most important factors is the inadequate balance 
between oxygen delivery $\left(\mathrm{DO}_{2}\right)$ and oxygen consumption $\left(\mathrm{VO}_{2}\right)$, and factors associated with this imbalance include hemodilution, low hemoglobin levels, and hypotension [2].

On the other hand, a number of predictive scores based on preoperative risk factors have been developed, such as the Cleveland Clinic Score (CCS), the most widely used and validated tool for not only RRT prediction, but also for the identification of severe AKI. It was first developed in 2012, but more recently, nadir intraoperative hematocrit has been added in order to improve the area under the curve (AUC), especially for patients without preexisting chronic kidney disease. The original score considers sex, presence of congestive heart failure, low left ventricular ejection fraction, preoperative use of intra-aortic balloon pump (IABP), chronic obstructive pulmonary disease (COPD), previous cardiac surgery, emergency surgery, type of surgery, and preoperative creatinine [3].

Another well-established predictive score is the European System for Cardiac Operative Risk Evaluation II (EuroSCORE II), a cardiac risk model for predicting mortality after cardiac surgery that was updated in 2012 from the previous EuroSCORE published in 1999 [4]. Even though it is not its aim, studies have shown an association between EuroSCORE and CSA-AKI [5], but again, it is better able to discriminate severe AKI.

Even though AKI that requires RRT is the scenario with the worst outcome, non-severe AKI, the most common form of AKI associated with cardiac surgery, has also been proven to be independently related to all-cause mortality [6]. Birnie et al. created the Leicester score (LS) to predict CSA-AKI of any stage in a British cohort, and it showed better discrimination ability compared to Euroscore II and the CCS [5]. The model included age, sex, BMI, smoking habits, dyspnea, diabetes, peripheral vascular disease, hypertension, preoperative hemoglobin, preoperative estimated glomerular filtration rate, time from catheterism to surgery, presence of triple vessel disease, ejection fraction, emergency surgery, and type of surgery. This scoring system was created in 2014, and since then, it has only been used to identify patients who are at risk in one German study, which was published in 2020 by Grieshaber et al., in which the prediction of all stages of AKI was not possible using the CCS but was possible when using the LS [7]. The variables that are included in the three mentioned scores are described in Table 1.

Table 1. Variables included in the EuroSCORE II, Cleveland Clinic Score, and Leicester score.

\begin{tabular}{|c|c|c|}
\hline Euroscore II & Cleveland Clinic Score & Leicester Score \\
\hline Age & - & Age \\
\hline \multicolumn{3}{|c|}{ Gender } \\
\hline $\begin{array}{l}\text { Preoperative renal function } \\
\text { (Cockroft-Gault formula, } \\
\mathrm{ml} / \text { min): }>85,50-85,<50 \\
\text { dialysis treatment }\end{array}$ & $\begin{array}{l}\text { Preoperative renal function } \\
\text { (creatinine, } \mathrm{mg} / \mathrm{dL} \text { ): }<1.2 \\
\mathrm{mg} / \mathrm{dL}, 1.2-2.1, \geq 2.1\end{array}$ & $\begin{array}{c}\text { Renal function } \\
\text { (Cockroft-Gault formula, } \\
\mathrm{ml} / \mathrm{min}):>90-60-89,30-59 \\
<30\end{array}$ \\
\hline Poor mobility & - & - \\
\hline Chronic lung disease & COPD requiring treatment & - \\
\hline Previous cardiac surgery & Previous cardiac surgery & - \\
\hline Active endocarditis & - & - \\
\hline Critical preoperative state & Preoperative use of IABP & - \\
\hline $\begin{array}{l}\text { Diabetes mellitus on insulin } \\
\text { therapy }\end{array}$ & $\begin{array}{l}\text { Diabetes mellitus on insulin } \\
\text { therapy }\end{array}$ & Diabetes mellitus \\
\hline NYHA class (I-IV) & Heart failure & NYHA class (I-IV) \\
\hline Class IV angina ${ }^{a}$ & - & - \\
\hline $\begin{array}{l}\text { Left ventricular function }(\%) \text { : } \\
\quad>50,31-50,21-30,<21\end{array}$ & Left ventricular function $<35 \%$ & $\begin{array}{l}\text { Left ventricular function (\%): } \\
\quad \geq 50,40-49,<40\end{array}$ \\
\hline
\end{tabular}


Table 1. Cont.

\begin{tabular}{|c|c|c|}
\hline Euroscore II & Cleveland Clinic Score & Leicester Score \\
\hline $\begin{array}{l}\text { Recent miocardial infarction } \\
\text { (90 days) }\end{array}$ & - & - \\
\hline $\begin{array}{l}\text { Pulmonary hypertension: } \\
\text { ystolic arterial pressure } 31-55 \\
\mathrm{mmHg},>55\end{array}$ & - & - \\
\hline $\begin{array}{l}\text { Urgency; (elective, urgent, } \\
\text { emergency, salvage) }\end{array}$ & Emergency surgery & $\begin{array}{l}\text { Urgency (elective, urgent, } \\
\text { emergency) }\end{array}$ \\
\hline $\begin{array}{l}\text { Type of surgery: isolated } \\
\text { CABG, non-CABG, } 2 \\
\text { procedures, } 3 \text { procedures }\end{array}$ & $\begin{array}{c}\text { Type of surgery: CABG, valve, } \\
\text { CABG + valve, other }\end{array}$ & $\begin{array}{c}\text { Type of surgery: CABG, single } \\
\text { valve, CABG + valve, } \\
\text { other/multiple }\end{array}$ \\
\hline Surgery on thoracic aorta & - & - \\
\hline- & - & $\begin{array}{c}\text { Body mass index }\left(\mathrm{kg} / \mathrm{m}^{2}\right) \text { : } \\
<20,20-24,25-29,30-34,>34\end{array}$ \\
\hline - & - & $\begin{array}{l}\text { Smoking habit: never, } \\
\text { ex-smoker, current }\end{array}$ \\
\hline- & - & Hypertension \\
\hline- & - & Peripheral vascular disease \\
\hline - & - & $\begin{array}{l}\text { Preoperative hemoglobin } \\
(\mathrm{g} / \mathrm{dL})(<10,10-11.9, \geq 12)\end{array}$ \\
\hline- & - & Triple vessel disease \\
\hline - & - & $\begin{array}{l}\text { Time from catheterism to } \\
\text { surgery }\end{array}$ \\
\hline
\end{tabular}

COPD: chronic obstructive pulmonary disease, CABG: coronary artery bypass grafting; IABP: intra-aortic balloon pump; NYHA: New York Heart Association. (a) Canadian Cardiovascular Society criteria.

The aim of this study was to identify risk factors for CSA-AKI in a Spanish cohort and to assess the performance of the LS in the same cohort.

\section{Material and Methods}

We conducted a unicentric retrospective study of patients admitted to Hospital Clínic de Barcelona requiring cardiac surgery with cardio-pulmonary bypass (CPB) from January 2015 to December 2015. The inclusion criteria were patients over 18 years old who were operated on for cardiac surgery (valve substitution (VS), Coronary Artery Bypass Graft $(\mathrm{CABG})$, or a combination of both procedures requiring $\mathrm{CPB}$. All stages of chronic kidney disease were included. Patients who were already in chronic dialysis therapy, renal transplant recipients, or those who suffered an AKI just before the surgery were not included in the study. Additionally, emergent surgeries, patients with IABP use, patients who died during surgery, and patients with endocarditis were excluded. The Ethics Committee of our institution approved the study.

\subsection{Data Colection and Definitions}

Clinical, epidemiological, and laboratory variables were collected from the Electronic Health Records of our institution $\left(\mathrm{SAP}^{\circledR}\right)$. For every patient, data regarding their medical history, surgical characteristics, intraoperative variables, $24 \mathrm{~h}$ monitoring in the intensive care unit (ICU), and renal function evolution until discharge were collected. For patients requiring RRT, its duration was also recorded.

The LS, CCS, Euroscore II, and Charlson Index were calculated with the information from the pre-anesthesia visit and/or patient admission report.

The intraoperative variables that were recorded were aortic cross-clamp time (ischemia time) and CPB time, use of furosemide, use of vasoactive drugs, or need for transfusion. The post-operative variables included monitoring of the first $24 \mathrm{~h}$ in the ICU and whether 
the patient was consistent in terms of the use of vasoactive drugs, use of furosemide, and need for transfusion. Finally, seriated serum creatinine $(\mathrm{sCr})$ and estimated glomerular filtration rate (eGFR) values were collected throughout the admission period.

\subsection{Definitions}

CSA-AKI was defined using the Kidney Disease Improving Global Outcomes (KDIGO) criteria: serum creatinine increase $\geq 0.3 \mathrm{mg} / \mathrm{dl}$ within $48 \mathrm{~h}$ or $\geq 1.5$ - to two-fold $\mathrm{sCr}$ increase from baseline within one week after surgery. Due to the nature of the study, the urinary output criteria were not included. Moderate AKI was defined as a $\mathrm{sCr}$ increase of 2.0-2.9 times from baseline. Severe AKI was defined as a sCrincrease of $\geq 3$ times from baseline, an increase of $0.5 \mathrm{mg} / \mathrm{dL}$ if baseline $\mathrm{sCr} \geq 4.0 \mathrm{mg} / \mathrm{dl}$, or initiation of RRT [8]. Baseline creatinine was considered as the value obtained $24 \mathrm{~h}$ before surgery. AKI duration was counted since the AKI diagnosis until sCr returned to the baseline value with or without an increase of $0.3 \mathrm{mg} / \mathrm{dL}$.

\subsection{Statistics}

The study variables are expressed as mean \pm standard deviation (SD) if a normal distribution was observed or as the median and interquartile range (IQR)otherwise. Categorical variables were expressed as an absolute value (n) and relative (\%) frequency. P values less than 0.05 were considered significant. Variables associated with the risk of CSA-AKI were assessed by logistic regression in univariate analysis, and those with statistical significance were included in the multivariate analysis, excluding score variables. To test the performance of the LS, we calculated the area under the receiver-operating characteristic curve (AUC) to assess the discrimination. We applied the Hosmer-Lemeshow goodness-of-fit test to assess its calibration. To compare ROC curves, we used DeLong's test. A P-value above 0.05 indicates acceptable calibration. The statistical analysis was conducted using SPSS v.25 (SPSS Inc, Chicago, IL, USA).

\section{Results}

\subsection{Baseline Characteristics}

During the study period, 444 patients were included. Table 2 shows the baseline characteristics of the overall population. A total of $64.2 \%$ of the patients were male with an age $\geq 75$ years old in $30.9 \%$ of the cases and a median age of 69 years. Hypertension was the most prevalent comorbidity $(76.1 \%)$, with obesity being observed in $34 \%$ of patients and diabetes being observed in $35.3 \%$ of patients. As for peripheral vascular disease, it was only diagnosed in $9.5 \%$ of the patients. Median baseline creatinine was $0.9 \mathrm{mg} / \mathrm{dL}$ (IQR $0.73-1.06$ ), and $19.4 \%$ of the patients had an eGFR $<60 \mathrm{~mL} / \mathrm{min}$. The most common procedure was VS, and $10.6 \%$ of the patients had undergone previous cardiac surgery. Anemia (hemoglobin $<120 \mathrm{~g} / \mathrm{L}$ ) was present in $19.6 \%$ of the patients before cardiac surgery.

Table 2. Baseline characteristics.

\begin{tabular}{cc}
\hline $\mathbf{n}=\mathbf{4 4 4}$ & $\mathbf{n}(\mathbf{\%}) /$ Median (IQR)/Mean+/-SD \\
\hline Sex (\%man) & $285(64.2)$ \\
\hline Age (years) & $69(61-76)$ \\
$\geq 75$ years & $137(30.9)$ \\
\hline History of smoking habit & $213(49)$ \\
\hline Diabetes & $157(35.36)$ \\
Diabetes with insulin therapy & $42(9.45)$ \\
\hline Hypertension & $338(76.1)$ \\
\hline BMI $\left(\mathrm{kg} / \mathrm{m}^{2}\right)$ & $28.33+/-4.47$ \\
BMI $\geq 30$ & $136(34.1)$ \\
\hline
\end{tabular}


Table 2. Cont.

\begin{tabular}{cc}
\hline $\mathbf{n}=\mathbf{4 4 4}$ & $\mathbf{n}(\mathbf{\%}) / \mathbf{M e d i a n}(\mathbf{Q Q R}) / \mathbf{M e a n}+/-\mathbf{S D}$ \\
\hline Anemia & $87(19.6)$ \\
Hemoglobin $(\mathrm{g} / \mathrm{L})$ & $134(123-143)$ \\
Hematocrit $(\%)$ & $39(36-42)$ \\
\hline Peripheral vascular disease & $42(9.5)$ \\
\hline Low ejection fraction $(<40 \%)$ & $45(10.13)$ \\
\hline Creatinine $(\mathrm{mg} / \mathrm{dL})$ & $0.9(0.73-1.06)$ \\
EGFR(ml/min) & $83.3(65-91)$ \\
EGFR $60 \mathrm{~mL} / \mathrm{min}$ & $86(19,37)$ \\
CKD EIII & $75(87.2)$ \\
CKD EIV & $11(12.8)$ \\
\hline Previous cardiac surgery & $47(10.6)$ \\
\hline Procedure & Valve surgery: $199(44.8)$, \\
& CABG: $171(38.5)$ \\
\hline Charlson index & Valve + CABG: $74(16.7)$ \\
\hline Euroscore II & $4(3-5)$ \\
\hline Cleveland Clinic Score & $1.77(1.08-3.02)$ \\
\hline Leicester Score & $0.4(0.4-1.8)$ \\
\hline
\end{tabular}

BMI: body mass index; EGFR: estimated glomerular filtration rate; CKD E III: chronic kidney disease stage III; CKD EIV: Chronic kidney disease stage IV; IQR: interquartile range; SD: standard deviation; CABG: coronary artery bypass grafting.

\subsection{Surgical Characteristics and Post-Intervention Lengh of Stay}

Surgical characteristics included a median CPB time of 91.5 (IQR 72-117) minutes and a median ischemia time of 65 (80-80.25) minutes. During the intervention, 115 patients $(26 \%)$ required blood transfusion. As for vasoactive drugs, phenylephrine and or noradrenaline were used in $67 \%$ of the patients, dobutamine was used in $44.2 \%$, and nitroglycerine/nitroprusside was used in $34.5 \%$. Furosemide was used in 114 patients (25.7\%), and ultrafiltration was used in $14(3.15 \%)$.

As for the first $24 \mathrm{~h}$ in the ICU, furosemide was used in 201 patients (45.9\%). The most common vasoactive agents were vasodilators (nitroglicerine or nitroprusside), which were used in $42.3 \%$ of the patients, followed by dobutamine, which was used in $45.2 \%$ of the patients, followed by noradrenaline, which was administer to $35 \%$ of the patients.

The post-surgical length of stay was a median of 9 days (IQR 7-13), and 9 patients died during admission (2\%).

\subsection{AKI Characteristics}

A total of 171 patients (38.5\%) developed AKI during the first week after cardiac surgery. Its characteristics are described in Table 3. Of note, the most frequent form of AKI was mild AKI, which was present in 105 patients (61.4\%). From all of the cases of mild AKI, almost $50 \%$ only met the ">0.3 mg/dL in $48 \mathrm{~h}$ " criteria. Stage 3 AKI developed in 26 patients, 15 of whom required RRT. A total of $66.7 \%$ of the AKI cases met the criteria within the first $24 \mathrm{~h}$, and the median duration until total recovery was 3 days. Two patients required dialysis at discharge. There were no differences in the baseline and discharge $\mathrm{sCr}$ and EGFR in all of the patients who were discharged without RRT (0.85 (0.68-1.04), 87 (64-91), respectively). 
Table 3. Summary of acute kidney injury characteristics.

\begin{tabular}{cc}
\hline AKI Stages & Days between Surgery and AKI Start \\
\hline AKI stage 1: $105(61,4 \%) \rightarrow 49$ met only the & Median time from surgery to AKI (1 (1-2) \\
" $>0.3 \mathrm{mg} / \mathrm{dL}$ in $48 \mathrm{~h} "$ criteria $(46.2 \%)$ & First $24 \mathrm{h:} 114(66.7 \%)$ \\
AKI stage $2: 40(23.4 \%)$ & $48 \mathrm{~h}: 36(22.8 \%)$ \\
AKI stage 3: $26(15,2 \%) \rightarrow 15$ with dialysis & $72 \mathrm{~h}: 10(5.85 \%)$ \\
requirement $(57.7 \%)$ & $>72 \mathrm{~h}: 11(6.4 \%)$ \\
\hline AKI duration & Dialysis technique \\
\hline Median duration time (days): $3(1-6)$ & Intermittent hemodialysis: 6 patients \\
24 h: 50 patients $(29.24 \%)$ & CRRT: 5 patients \\
48 h: 26 patients $(15.2 \%)$ & Both: 4 patients \\
72 h: 23 patients $(13.45 \%)$ & * Median intermittent hemodialysis sessions: \\
$>72$ h: 72 patients $(42.1 \%)$ & 2 (IQR 1-4) \\
\hline
\end{tabular}

AKI: acute kidney injury; CRRT: continuous renal replacement therapy.

\subsection{Preoperative and Intraoperative Risk Factors for CSA-AKI}

A univariate analysis was performed to identify preoperative and intraoperative risk factors to assess the performance of the different risk scores (CCS, LS, and Euroscore II). Table 4.

Table 4. Risk factors for cardiac surgery-associated acute kidney injury: univariate analysis.

\begin{tabular}{|c|c|c|c|c|c|}
\hline & $\begin{array}{c}\text { Total } \\
(\mathrm{n}=444)\end{array}$ & $\begin{array}{c}\text { No AKI }(\mathrm{n}= \\
273,61.5 \%)\end{array}$ & $\begin{array}{c}\text { AKI } \\
(\mathrm{n}=171 \\
38.5 \%)\end{array}$ & OR (IQR) & $p$ Value \\
\hline \multicolumn{6}{|l|}{ PREOPERATIVE } \\
\hline Age $\geq 75$ (years) & $137(30.9)$ & $70(25.6)$ & $67(39.2)$ & $\begin{array}{c}1.868 \\
(1.24-2.815)\end{array}$ & 0.003 \\
\hline Sex (\%Male) & $285(64.2)$ & $168(61.5)$ & $117(68.4)$ & $\begin{array}{c}1.354 \\
(0.904-2.029) \\
\end{array}$ & 0.142 \\
\hline $\mathrm{BMI}>30$ & $136(34.1)$ & $76(31.3)$ & $60(35.1)$ & $\begin{array}{c}1.373 \\
(0.901-2.093) \\
\end{array}$ & 0.140 \\
\hline Ever smoked & $213(49)$ & $130(48.7)$ & $83(48.5)$ & $\begin{array}{c}1.029 \\
(0.699-1.514)\end{array}$ & 0.884 \\
\hline Diabetes & 157 (35.36) & $89(32.6)$ & $67(39.4)$ & $\begin{array}{c}1.365 \\
(0.917-2.031)\end{array}$ & 0.125 \\
\hline Hypertension & $338(76.1)$ & $194(71.1)$ & $144(84.2)$ & $\begin{array}{c}2.172 \\
(1.334-3.535)\end{array}$ & 0.002 \\
\hline $\begin{array}{c}\text { Peripheral vascular } \\
\text { disease }\end{array}$ & $42(9.5)$ & $13(4.8)$ & $29(16.9)$ & $\begin{array}{c}4.085 \\
(2.058-8.106) \\
\end{array}$ & $<0.001$ \\
\hline $\mathrm{EF}<40 \%$ & $45(10.13)$ & $22(8.1)$ & $23(13.4)$ & $\begin{array}{c}1.773 \\
(0.9455-3.292)\end{array}$ & 0.070 \\
\hline Anemia & 87 (19.6) & $41(15)$ & $46(26.9)$ & $\begin{array}{c}2.099 \\
(1.307-3.372)\end{array}$ & 0.002 \\
\hline Creatinine (mg/dL) & $\begin{array}{c}0.9 \\
(0.73-1.06)\end{array}$ & $0.86(0.7-1)$ & $\begin{array}{c}0.99 \\
(0.79-1.25) \\
\end{array}$ & $\begin{array}{c}6.778 \\
(3.405-13.49)\end{array}$ & $<0.001$ \\
\hline eGFR (ml/min) & $83.3(65-91)$ & $85(71-91)$ & $72(53-86)$ & $\begin{array}{c}0.964 \\
(0.955-0.975)\end{array}$ & $<0.001$ \\
\hline $\mathrm{EGFR}<60 \mathrm{~mL} / \mathrm{min}$ & $86(19.37)$ & $32(11.7)$ & $54(31.6)$ & $\begin{array}{c}3.571 \\
(2.190-5.822)\end{array}$ & $<0.001$ \\
\hline Only CABG & $171(38.5)$ & $116(42.5)$ & $55(32.2)$ & $\begin{array}{c}0.642 \\
(0.43-0.958)\end{array}$ & 0.03 \\
\hline
\end{tabular}


Table 4. Cont.

\begin{tabular}{|c|c|c|c|c|c|}
\hline & $\begin{array}{c}\text { Total } \\
(n=444)\end{array}$ & $\begin{array}{c}\text { No AKI (n = } \\
273,61.5 \%)\end{array}$ & $\begin{array}{c}\text { AKI } \\
(\mathrm{n}=171 \\
38.5 \%)\end{array}$ & OR (IQR) & $p$ Value \\
\hline Leicester score & $\begin{array}{c}18.45(11.12- \\
30.94)\end{array}$ & $\begin{array}{c}15.17 \\
(9.2-22.45)\end{array}$ & $\begin{array}{c}26.81 \\
(16.4-41.42)\end{array}$ & $\begin{array}{c}1.058 \\
(1.042-1.073)\end{array}$ & $<0.001$ \\
\hline Euroscore II & $\begin{array}{c}1.77 \\
(1.08-3.02)\end{array}$ & $\begin{array}{c}1.42 \\
(0.95-2.61)\end{array}$ & $\begin{array}{c}2.34 \\
(1.34-3.89)\end{array}$ & $\begin{array}{c}1.203 \\
(1.103-1.306)\end{array}$ & $<0.001$ \\
\hline $\begin{array}{c}\text { Cleveland Clinic } \\
\text { Score }\end{array}$ & $0.4(0.4-1.8)$ & $0.4(0.4-1.8)$ & $1.8(0,4-1.8)$ & $\begin{array}{c}1.188 \\
(1.081-1.306)\end{array}$ & $<0.001$ \\
\hline Charlson Index & $4(3-5)$ & $3(2-5)$ & $4(3-6)$ & $\begin{array}{c}1.373 \\
(1.226-1.537)\end{array}$ & $<0.001$ \\
\hline \multicolumn{6}{|l|}{ INTRAOPERATIVE } \\
\hline Blood transfusion & $115(26)$ & $61(22.4)$ & $54(31.6)$ & $\begin{array}{c}1.610 \\
(1.047-2.477)\end{array}$ & 0.030 \\
\hline Vasodilator agents & $153(34.5)$ & $107(39.2)$ & $46(26.9)$ & $\begin{array}{c}0.576 \\
(0.379-0.873)\end{array}$ & 0.009 \\
\hline Dobutamine & $198(45.2)$ & $118(43.2)$ & $78(45.6)$ & $\begin{array}{c}1.114 \\
(0.758-1.637)\end{array}$ & 0.584 \\
\hline Furosemide use & $114(25.7)$ & $62(22.7)$ & $52(30.4)$ & $\begin{array}{c}1.5 \\
(0.974-2.310)\end{array}$ & 0.066 \\
\hline $\begin{array}{l}\text { Vasoconstrictor } \\
\text { agents }\end{array}$ & $298(67.12)$ & $150(54.9)$ & $148(86.5)$ & $\begin{array}{c}1.543 \\
(1.039-2.292)\end{array}$ & 0.032 \\
\hline CPB time (min) & $\begin{array}{c}91.5 \\
(72-117)\end{array}$ & $88(71-110)$ & $100(74-127)$ & $\begin{array}{c}1.007 \\
(1.002-1.012)\end{array}$ & 0.005 \\
\hline $\mathrm{CPB}$ time $>90 \mathrm{~min}$ & $226(51.4)$ & $124(45.8)$ & $102(59.6)$ & $\begin{array}{c}1.805 \\
(1.222-2.666)\end{array}$ & 0.003 \\
\hline \multirow{2}{*}{$\begin{array}{c}\text { Ischemia time } \\
\text { Ischemia time }>70 \\
\text { min }\end{array}$} & $\begin{array}{c}65 \\
(50-80.25)\end{array}$ & $60(48-80)$ & $75(54-92)$ & $\begin{array}{c}1.012 \\
(1.005-1.018)\end{array}$ & $<0.001$ \\
\hline & $179(41.2)$ & $91(33.8)$ & $88(51.5)$ & $\begin{array}{c}2.235 \\
(1.504-3.324)\end{array}$ & $<0.001$ \\
\hline
\end{tabular}

OR: odds ratio; IQR: interquartile range; AKI: acute kidney injury; BMI: body mass index; EF: ejection fraction EGFR: estimated glomerular filtration rate; CABG: coronary artery bypass grafting; CPB: cardiopulmonary bypass.

Of the included preoperative risk factors, those who were associated with CSA-AKI were over 75 years of age (odds ratio (OR) $1.868(1.24-2.815), p=0.003)$, had hypertension (OR 2.172 (1.334-3.535), $p=0.002)$, peripheral vascular disease (OR 4.085 (2.058-8.106), $p<0.001$ ), anemia (OR 2.099 (1.307-3.372), $p=0.002)$, and higher $\mathrm{sCr}$ and lower EGFR (OR 6.778 (3.405-13.49) and OR 0.964(0.955-0.975), respectively, $p<0.001$ ). Lower eGFR remained significant when categorized for EGFR $<60 \mathrm{~mL} / \mathrm{min}$. Bypass surgery alone was the only variable associated with lower incidence of AKI (OR 0.642 (0.43-0.958), $p=0.03$.

The three scores were significantly associated with CSA-AKI, with an OR of 1.058 (1.042-1.073) for the LS, 1.203 (1.103-1.306) for Euroscore II, and 1.188 (1.081-1.306) for the CCS. The Charlson index was also significantly associated with AKI, with an OR of 1.373 (1.226-1.537).

Of the included intraoperative risk factors, the need for blood transfusion was significantly associated with the outcome (OR $1.610(1.047-2.477), p=0.03)$, as was the use of noradrenenaline or phenilephrine (OR $1.543(1.039-2.292), p=0.032$ ), while the use of vasodilators such as ntroglycerine or nitroprusside appeared to be protectors (OR 0.576 (0.379-0.873), $p=0.009$ ). Longer $\mathrm{CPB}$ and ischemia times were also associated with the outcome (OR 1.007 (1.002-1.012), $p=0.005$ and OR $1.012(1.005-1.018) p<0.001$, respectively).

The statistically significant variables were introduced in a multivariate logistic regression analysis, where the variables that remained associated with the outcome were: 
hypertension (OR 1.883 (1.086-3.265), $p=0.024)$, EGFR < $60 \mathrm{~mL} / \mathrm{min}$ (2.365 (1.375-4.070), $p=0.002)$, and peripheral vascular disease $(4.66(2.134-10.177), p<0.001)$. Ischemia time $>70$ min almost reached statistical significance, with a $p$ value of 0.058 . (Table 5).

Table 5. Multivariate analysis of risk factors associated with cardiac surgery-associated acute kidney injury.

\begin{tabular}{ccc}
\hline Variable & OR (CI) & $p$-Value \\
\hline Age $\geq 75$ years & $1.483(0.928-2.371)$ & 0.099 \\
\hline Hypertension & $1.883(1.086-3.265)$ & 0.024 \\
\hline EGFR $<60 \mathrm{~mL} / \mathrm{min}$ & $2.365(1.375-4.070)$ & 0.002 \\
\hline Anemia & $1.642(0.918-2.939)$ & 0.095 \\
\hline Bypass & $0.838(0,503-1.397)$ & 0.499 \\
\hline Peripheral vascular disease & $4.66(2.134-10.177)$ & $<0.001$ \\
\hline Blood transfusion & $0.87(0.509-1.487)$ & 0.608 \\
\hline Vasopressors agents & $1.261(0.784-2.027)$ & 0.34 \\
\hline Vasodilators agents & $0.694(0.412-1.168)$ & 0.169 \\
\hline CPB time $>90$ min & $1.019(0.553-1.879)$ & 0.951 \\
\hline Isquemia time $>70$ min & $1.844(0.979-3.473)$ & 0.058 \\
\hline OR: odds ratio; CI: confidence interval· EGFR: estimated glomerular filtration rate; CPB: cardiopulmonary bypass.
\end{tabular}

\subsection{Leicester Score Performance}

The diagnostic utility of the Leicester score was compared with two previously published scores that have been widely validated: the CCS and Euroscore II. Using the original formula, we found an AUC of $0.721(0.671-0.771)$ for any grade of CSA-AKI and a goodness-of-fit $\chi^{2}=10.61(p=0.225)$ for the LS. Both discrimination and calibration were better compared to the CCS and Euroscore II (Table 6, Figure 1), and the difference between curves was statistically significant (Table 7). Compared to the original validation cohort, LS had similar accuracy (AUC 0.73).

Table 6. Discrimination (area under ROC curves) for the different scores and calibrations (HosmerLemshow tests).

\begin{tabular}{cccc}
\hline & \multicolumn{2}{c}{ Discrimination } & Calibration \\
\hline & AUC (95\% CI) & $p$ Value & ${\text { Chi Square } \boldsymbol{p} \text { Value }^{\mathbf{a}}}$ \\
\hline Leicester score & $0.721(0.671-0.771)$ & $<0.001$ & 10.10 .225 \\
\hline Cleveland Clinic Score & $0.595(0.54-0.65)$ & 0.001 & 2.6310 .105 \\
\hline Euroscore & $0.662(0.611-0.713)$ & $<0.001$ & 11.480 .176
\end{tabular}

a Higher values indicate better calibration. ROC: receiver operating characteristic; AUC: area under the curve; $\mathrm{CI}$ confidence interval.

Table 7. Comparison between ROC curves by DeLong's test.

\begin{tabular}{cccc}
\hline & CCS-Euroscore II & CCS-LS & Euroscore II-LS \\
\hline Difference between areas & 0.067 & 0.126 & 0.059 \\
\hline Stadard Error $(\mathrm{CI})$ & $0.025(0.017-0.112)$ & $0.030(0.067-0.185)$ & $0.027(0.006-0.112)$ \\
\hline Z statistic & 2.633 & 4.203 & 2.199 \\
\hline$p$-Value & 0.009 & $<0.001$ & 0.028
\end{tabular}

ROC: receiver operating characteristic CCS: Cleveland Clinic Score; LS: Leicester Score; CI: confidence interval. 


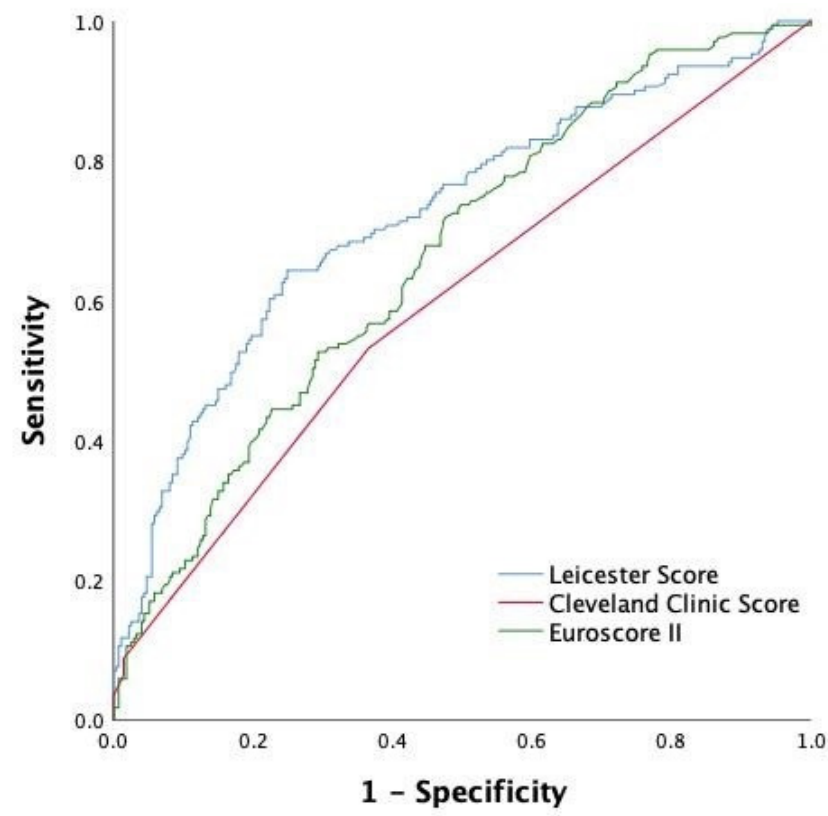

Figure 1. Receiver operating characteristic curve of each scoring system (Leicester score, Cleveland Clinic score, and Euroscore II).

\section{Discussion}

In this retrospective unicentric study, we evaluated risk factors for CSA-AKI and assessed the performance of the LS in a Spanish cohort. Preoperative hypertension, chronic kidney disease (CKD), peripheral vascular disease, and longer ischemia time were the variables that remained associated with the outcome. The LS showed the best discrimination and calibration compared to classic scores.

Our results do not differ from classical studies. In 2016, Yi Q et al. conducted a meta-analysis of the studies that assessed the risk factors for CSA-AKI (CS and/or CABP surgeries with $\mathrm{CPB}$ ). The authors identified hypertension, preoperative $\mathrm{SCr}$ level, peripheral vascular disease, respiratory system disease, diabetes, cerebrovascular disease, low cardiac output, New York Heart Association (NYHA) classification class III/IV, emergency surgery, infection, re-intervention, and use of IABP as preoperative risk factors for CSA-AKI [9].

Since the presence of CKD seems to be one of the most important risk factors in the different cohorts, specific studies have also been performed in order to identify risk factors for patients with impaired kidney function. In 2020, Fu HS et al. described the risk factors for CSA-AKI in patients with eGFR $<30 \mathrm{~mL} / \mathrm{min}$, showing that only a high preoperative serum creatinine and decreased $\mathrm{CPB}$ target temperature were significant risk factors for postoperative AKI in their multivariate analysis [10]. On the other hand, other studies showed that baseline $\mathrm{s} C \mathrm{r}$ seem to be associated with CSA-AKI, only in patients with eGFR $<60 \mathrm{~mL} / \mathrm{min}$ [11].

$\mathrm{CPB}$ is a major intraoperative factor contributing to CSA-AKI. The pathophysiology of kidney injury during $\mathrm{CPB}$ is complex and multifactorial. There are four main pathways that lead to AKI during CPB: oxygen supply/demand mismatch, the activation of an inflammatory response, haemolysis, and lipid microemboli [12-15]. All of these mechanisms explain why longer $\mathrm{CPB}$ and ischemia times are classically associated with AKI [16].

Hemodynamics remain of vital importance in cardiac surgery with CPB. Renal oxygenation is determined by an equilibrium between oxygen delivery $\left(\mathrm{RDO}_{2}\right)$ and oxygen consumption $\left(\mathrm{RVO}_{2}\right)$. Cardiac output $(\mathrm{CO})$ and oxygen arterial content $\left(\mathrm{CaO}_{2}\right)$ are the two main determinants of $\mathrm{RDO}_{2}$. Therefore, the influence of low hematocrit [17] and low mean arterial pressure on CSA-AKI can be pathophysiologically explained. Nevertheless, there is inconclusive evidence on the relationship between the MAP targeted during $\mathrm{CPB}$ and the incidence of CSA-AKI [18]. On the other hand, studies have shown that a greater 
difference in intraoperative MAP relative to preoperative MAP can be a risk factor. In a prospective study of 157 patients, Kenji et al. found that a drop in MAP of $>26 \mathrm{mmHg}$ was independently associated with the development of AKI following cardiac surgery [19]. This could explain why preoperative hypertension was also a risk factor for CSA-AKI in our cohort and could be the focus of intervention. As for peripheral vascular disease, it is not only a known risk factor for AKI but for other major complications, especially in patients undergoing CABG [20].

There is a need to identify patients who are at risk for CSA-AKI in order to include them in clinical trials. Since mild AKI has also been proven to be an independent risk factor for mortality, scores that assess the risk of AKI of any stage in combination with biomarkers of early renal damage should be the focus when designing intervention studies.

In this regard, results from the PrevAKI trial were published in 2017. In that trial, a KDIGO guidelines based strategy was performed in high-risk patients undergoing cardiac surgery, who were defined as having a urinary Tissue inhibitor of metalloproteinases-2 (TIMP-2) $x$ Insulin-like growth factor-binding protein 7 (IGFBP7) > 0.3. AKI was significantly reduced with this intervention compared to in the controls [21]. Biomarkers were used to identify patients who were at a high risk of clinical AKI in order to use preventive strategies for the first time.

As for the scores, the CCS was validated for the prediction of postoperative AKI requiring RRT, although it has been used in other studies to predict all stages of AKI [3]. In contrast, the LS was validated for the prediction of all stages of AKI, as defined by KDIGO [5]. Hence, the last one appears to be the best method for the identification of a wider spectrum of patients.

The LS was first published in 2014. The model was developed using the Bristol and Birmingham center datasets, and it was externally validated using data from Wolverhampton center, which is also in United Kingdom. Diagnostic utility was compared to existing scores. The risk prediction score for any AKI stage $(\mathrm{AUC}=0.74(0.72,0.76))$ demonstrated better discrimination compared to the Euroscore and the CCS, and better calibration was also observed.

It was not until 2020 that this score was first used in an external study conducted by Grieshaber P et al. in a German center [7]. In the study, the authors tried to identify patients who were at a high risk for CSA-AKI by combining clinical risk stratification with either the CCS and LS and the early postoperative quantification of urinary biomarkers for AKI using (TIMP-2).(IGFBP7). Although the LS was predictive for all stages of AKI, the CCS was only predictive for stage 2 or 3 AKI. In this study, its AUC (0.601) was poor, so the LS performed markedly worse compared to in the validation cohort (AUC 0.73). Urinary (TIMP-2)_(IGFBP-7) quantification $4 \mathrm{~h}$ postoperatively did not add value to the predictive value of the clinical score. By contrast, in our study, the AUC (0.72) was similar to the validation cohort in the original study. This could be due to the higher EuroSCORE values in the German study (2.5 for no-AKI and 2.8, 6.0 and 8.8 for stages 1-3, respectively) compared to in our cohort. Even though the median values from the validation cohort are not available, they could be closer to our cohort. Based on the first external study, the performance of the LS could be considered weak, but our good results make the LS a promising scoring system that can be used by clinicians in future intervention studies in order to identify patients who are at risk for AKI.

Our study has some limitations. First, patients who were in a critical state (requiring emergency surgery or the use of IABP) or who had endocarditis were excluded. These patients were not excluded in the study where the LS was first validated, which makes our cohort not completely comparable. Critical patients are not the focus for clinical trials, so the good performance of the LS in our cohort could serve as the basis for designing intervention studies in patients wo are susceptible to developing AKI. This is a retrospective study that provides information about LS performance in a large cohort of patients, but prospective studies are needed in order to confirm and externally validate the LS. 
In conclusion, based on our results, preoperative hypertension in patients with CKD with or without peripheral vasculopathy could be a focus for intervention in future studies. The LS has proved to be a valid scoring system that could be used to identify patients who are at risk who could benefit from future intervention studies.

Author Contributions: Research idea and study design: A.M.A. and E.P.; data acquisition: A.M.A., A.L., and V.J.E.; data analysis and interpretation: A.M.A.; supervision and mentorship: E.P., I.R., P.M., C.I., M.B., E.S., J.R., M.C.S., and G.J.P.; E.Q. contributed with important intellectual content during manuscript drafting and approved the final version of the manuscript. All authors have read and agreed to the published version of the manuscript.

Funding: This research received no external funding.

Institutional Review Board Statement: The study was conducted in accordance with the Declaration of Helsinki, and approved by the Institutional Ethics Committee of Hospital Clinic de Barcelona (protocol code HCB/2019/0959; date of approval: 24th October 2019).

Informed Consent Statement: Patient consent was waived due to the retrospective nature of the study and since they cannot be identified.

Data Availability Statement: The data that support the findings of this study are available on request from the corresponding author (E.P).

Conflicts of Interest: The authors report no potential conflict of interest.

\section{References}

1. O'Neal, J.B.; Shaw, A.D.; Billings, F.T. Acute kidney injury following cardiac surgery: Current understanding and future directions. Crit. Care 2016, 20, 187. [CrossRef] [PubMed]

2. Liu, D.; Liu, B.; Liang, Z.; Yang, Z.; Ma, F.; Yang, Y.; Hu, W. Acute Kidney Injury following Cardiopulmonary Bypass: A Challenging Picture. Oxidative Med. Cell. Longev. 2021, 2021, 1-13. [CrossRef] [PubMed]

3. Crosina, J.; Lerner, J.; Ho, J.; Tangri, N.; Komenda, P.; Hiebert, B.; Choi, N.; Arora, R.C.; Rigatto, C. Improving the Prediction of Cardiac Surgery-Associated Acute Kidney Injury. Kidney Int. Rep. 2016, 2, 172-179. [CrossRef] [PubMed]

4. Nashef, S.A.; Roques, F.; Sharples, L.D.; Nilsson, J.; Smith, C.; Goldstone, A.R.; Lockowandt, U. EuroSCORE II. Eur. J. Cardiothorac Surg. 2012, 41, 734-744. [CrossRef]

5. $\quad$ Birnie, K.; Verheyden, V.; Pagano, D.; Bhabra, M.; Tilling, K.; Sterne, J.A.; Murphy, G.J.; UK AKI in Cardiac Surgery Collabortors. Predictive models for kidney disease: Improving global outcomes (KDIGO) defined acute kidney injury in UK cardiac surgery. Crit. Care 2014, 18, 606. [CrossRef]

6. Yang, Y.; Ma, J. Mild AKI is associated with mortality of patients who underwent cardiopulmonary bypass surgery. Exp. Ther. Med. 2020, 20, 2969-2974. [CrossRef] [PubMed]

7. Grieshaber, P.; Möller, S.; Arneth, B.; Roth, P.; Niemann, B.; Renz, H.; Böning, A. Predicting Cardiac Surgery-Associated Acute Kidney Injury Using a Combination of Clinical Risk Scores and Urinary Biomarkers. Thorac. Cardiovasc. Surg. 2019, 68, 389-400. [CrossRef]

8. Kellum, J.A.; Lameire, N.; KDIGO AKI Guideline Work Group. Diagnosis, evaluation, and management of acute kidney injury: A KDIGO summary (Part 1). Crit. Care 2013, 17, 204. [CrossRef]

9. Yi, Q.; Li, K.; Jian, Z.; Xiao, Y.-B.; Chen, L.; Zhang, Y.; Ma, R.-Y. Risk Factors for Acute Kidney Injury after Cardiovascular Surgery: Evidence from 2157 Cases and 49,777 Controls-A Meta-Analysis. Cardiorenal Med. 2016, 6, 237-250. [CrossRef]

10. Fu, H.-Y.; Chou, N.-K.; Chen, Y.-S.; Yu, H.-Y. Risk factor for acute kidney injury in patients with chronic kidney disease receiving valve surgery with cardiopulmonary bypass. Asian J. Surg. 2020, 44, 229-234. [CrossRef]

11. Lombardi, R.; Ferreiro, A. Risk factors profile for acute kidney injury after cardiac surgery is different according to the level of baseline renal function. Ren. Fail. 2008, 30, 155-160. [CrossRef] [PubMed]

12. Lee, C.-J.; Gardiner, B.S.; Smith, D.W. A cardiovascular model for renal perfusion during cardiopulmonary bypass surgery. Comput. Biol. Med. 2020, 119, 103676. [CrossRef] [PubMed]

13. Millar, J.E.; Fanning, J.P.; McDonald, C.I.; McAuley, D.F.; Fraser, J.F. The inflammatory response to extracorporeal membrane oxygenation (ECMO): A review of the pathophysiology. Crit. Care 2016, 20, 1-10. [CrossRef]

14. Spina, S.; Lei, C.; Pinciroli, R.; Berra, L. Hemolysis and Kidney Injury in Cardiac Surgery: The Protective Role of Nitric Oxide Therapy. Semin. Nephrol. 2019, 39, 484-495. [CrossRef]

15. Issitt, R.; James, T.; Walsh, B.; Voegeli, D. Do lipid microemboli induce acute kidney injury during cardiopulmonary bypass? Perfusion 2017, 32, 466-473. [CrossRef]

16. Kumar, A.B.; Suneja, M.; Bayman, E.O.; Weide, G.D.; Tarasi, M. Association between Postoperative Acute Kidney Injury and Duration of Cardiopulmonary Bypass: A Meta-Analysis. J. Cardiothorac. Vasc. Anesthesia 2012, 26, 64-69. [CrossRef] 
17. Ranucci, M.; Aloisio, T.; Carboni, G.; Ballotta, A.; Pistuddi, V.; Menicanti, L.; Frigiola, A. Acute Kidney Injury and Hemodilution during Cardiopulmonary Bypass: A Changing Scenario. Ann. Thorac. Surg. 2015, 100, 95-100. [CrossRef]

18. Mazzone, A.L.; Baker, R.A.; Gleadle, J.M. Mending a broken heart but breaking the kidney. Nephrology 2016, 21, 812-820. [CrossRef]

19. Kanji, H.D.; Schulze, C.J.; Hervas-Malo, M.; Wang, P.; Ross, D.B.; Zibdawi, M.; Bagshaw, S.M. Difference between pre-operative and cardiopulmonary bypass mean arterial pressure is independently associated with early cardiac surgery-associated acute kidney injury. J. Cardiothorac. Surg. 2010, 5, 71. [CrossRef]

20. Rihal, C.S.; Sutton-Tyrrell, K.; Guo, P.; Keller, N.M.; Jandova, R.; Sellers, M.A.; Schaff, H.V.; Holmes, D.R., Jr. Increased incidence of periprocedural complications among patients with peripheral vascular disease undergoing myocardial revascularization in the bypass angioplasty revascularization investigation. Circulation 1999, 100, 171-177. [CrossRef]

21. Meersch, M.; Schmidt, C.; Hoffmeier, A.; Van Aken, H.; Wempe, C.; Gerss, J.; Zarbock, A. Prevention of cardiac surgery-asscited AKI by implementing the KDIGO guidelines in high risk patients identified by biomarkers: The PrevAKI randomized controled trial. Intensive Care Med. 2017, 43, 1551-1561. [CrossRef] [PubMed] 